\title{
Bleeding after tonsillectomy was associated to hypertension and dissection with diathermy, but not surgical experience
}

\author{
Karl Knoph ${ }^{1,2}$, Max Eriksson ${ }^{1,2}$ and Lovisa Farnebo ${ }^{1,2 *}$ \\ ${ }^{1}$ Department of Otorhinolaryngology-Head and Neck Surgery, Linköping University Hospital, 58185 Linköping, Sweden \\ ${ }^{2}$ Department of Biomedical and Clinical Sciences, Linköping University, Region of Östergötland, Linköping, Sweden
}

\begin{abstract}
Objective: To analyze risk factors for postoperative bleeding after tonsillectomy (TE), and differences in bleeding frequency between 2017 and 2018.

Study design: This is a retrospective cohort study.

Setting: The Department of Otorhinolaryngology - Head and Neck Surgery, region of Östergötland, Sweden.

Methods: This retrospective cohort study included all 402 consecutive cases of TE in the region of Östergötland, Sweden 2017-2018. Patients were followed for at least 30 days after surgery. Demographics, comorbidity, surgical experience, potential risk factors and postoperative complications were registered. The primary endpoint was postoperative bleeding.

Results: Twenty-four of 402 (6\%) patients had a postoperative bleeding after tonsillectomy. Hypertension and dissection with bipolar diathermy respectively were identified as independent, statistically significant risk factors for bleeding, in both uni- and multivariate analysis. Surgical experience was not significantly associated to bleedings after TE.

Conclusion: Hypertension and dissection with bipolar diathermy are individual risk factors for postoperative bleeding following tonsillectomy, but not surgical experience.
\end{abstract}

\section{Introduction}

According to the National Tonsil Surgery Register in Sweden (NTSRS), 54.524 tonsil surgeries were registered 2015-2019, averaging 10.900 per year [1]. Tonsillectomies (TE) were more common than tonsillotomies (TT) (TE 55\%, TT 45\%), and the majority of the patients were children and young adults. High age [2,3], male gender [2,4,5], hypertension [6], surgical indication [2], use of local anesthesia with adrenaline [7], smoking [8,9], high BMI [10] and ADHD [11], were risk factors for postoperative bleeding, according to the literature. An increased number of bleedings was reported between 1987 and 2013 [12], when 'hot surgical techniques' gained wider spread. During later years, a return to 'cold surgical techniques' $[2,13]$, and an increased number of TTs [14], have led to stable numbers of postoperative bleedings [15]. Convincing evidence indicate that dissection using cold steel instruments causes less postoperative bleeding than hot techniques such as bipolar diathermy, coblation, radiofrequency or ultracision $[16,17]$.

TE is a common surgery in Sweden, generally performed as an outpatient procedure. Postoperative bleeding causes personal suffering, often necessitating readmission and sometimes reoperation. Furthermore, bleedings are associated with costs for acute transportation, surgery, and hospitalization and a deeper understanding of preventable factors affecting the risk of bleeding is called for. A recent study using data from the NTSRS showed that, $4.5 \%$ of the patients having tonsil surgery in Sweden were rehospitalized because of bleeding within 30 days, (TT 1.1\% and TE 8.6\%) 2009-2018 [15]. NTSRS data for the region of Östergötland (RÖ) showed an unexplained difference in the rate of rehospitalization after tonsillectomy $2017(10.8 \%)$ versus 2018 (2.6\%) [1]. The aim of this study, was to analyze risk factors for postoperative bleeding after TE, using demographics, comorbidity, indication, methods for surgery and hemostasis, surgeon experience, and differences in rehospitalization rates 2017 and 2018.

\section{Methods}

Patients were identified using surgical codes registered in the electronic medical records, for all patients undergoing tonsil surgery during 2017-2018, in RÖ, Sweden. The region includes one regional and one university hospital. Patient medical charts were reviewed and parameters potentially influencing the risk of bleeding were collected (Table 1). Ethical approval was obtained from the regional ethics board, (2019-03687), and data has been handled according to Swedish law and regulations.

None of the TT patients in 2017 (109) suffered postoperative bleeding and were therefore excluded. Further analysis was made on the 402 patients having TE with or without other concurrent surgery.

${ }^{\star}$ Correspondence to: Lovisa Farnebo, Department of OtorhinolaryngologyHead and Neck Surgery, Linköping University Hospital, 58185 Linköping, Sweden, Tel: +46702640330; E-mail: lovisa.farnebo@regionostergotland.se

Key words: tonsillectomy, postoperative bleeding, risk factors, postoperative complications, surgical experience, National Tonsil Surgery Register in Sweden

Received: May 04, 2020; Accepted: May 19, 2020; Published: May 22, 2020 
Table 1. Univariate analysis comparing patients with and without postoperative bleeding. Age presented as the median (lower and upper quartile). Other variables are presented as numbers (percentages)

\begin{tabular}{|c|c|c|c|}
\hline & $\begin{array}{l}\text { Reference } \\
\text { group } n=378\end{array}$ & $\begin{array}{l}\text { Post-op } \\
\text { bleeding n=24 }\end{array}$ & $\mathbf{p}$ \\
\hline \multicolumn{4}{|l|}{ Baseline characteristics } \\
\hline Age & $23(15 ; 40)$ & $26.5(19 ; 52)$ & 0.068 \\
\hline Age $<18$ years & $123(32.5 \%)$ & $2(8.3 \%)$ & \multirow[t]{2}{*}{0.013} \\
\hline Age $\geq 18$ years & $255(67.5 \%)$ & $22(91.7 \%)$ & \\
\hline Female & $201(53.2 \%)$ & $9(37.5 \%)$ & \multirow[t]{2}{*}{0.136} \\
\hline Male & $177(46.8 \%)$ & $15(62.5 \%)$ & \\
\hline Coagulopathy & $1(0.3 \%)$ & $1(4.2 \%)$ & 0.116 \\
\hline Hypertension & $16(4.2 \%)$ & $6(25.0 \%)$ & 0.001 \\
\hline Diabetes & $8(2.1 \%)$ & $1(4.2 \%)$ & 0.429 \\
\hline ADHD & $5(1.3 \%)$ & $1(4.2 \%)$ & 0.311 \\
\hline Smoking & $31(8.2 \%)$ & $5(20.8 \%)$ & 0.056 \\
\hline Overweight (all) & $171(45.2 \%)$ & $15(62.5 \%)$ & 0.124 \\
\hline Oral anticoagulants & $12(3.2 \%)$ & $2(8.3 \%)$ & 0.201 \\
\hline Previous TT & $15(4.0 \%)$ & $0(0.0 \%)$ & 1.000 \\
\hline Postoperative infection & $13(3.4 \%)$ & $3(12.5 \%)$ & 0.057 \\
\hline \multicolumn{4}{|l|}{ Surgical indication } \\
\hline Obstruction & $44(11.6 \%)$ & $3(12.5 \%)$ & 0.752 \\
\hline Chronic tonsillitis & $123(32.5 \%)$ & $7(29.2 \%)$ & 0.732 \\
\hline $\begin{array}{l}\text { Acute/former peritonsillar } \\
\text { abscess }\end{array}$ & $101(26.7 \%)$ & $5(20.8 \%)$ & 0.526 \\
\hline Complication of systemic illness & $2(0.5 \%)$ & $0(0.0 \%)$ & 1.000 \\
\hline Suspected malignancy & $67(17.7 \%)$ & $5(20.8 \%)$ & 0.783 \\
\hline Other indication & $17(4.5 \%)$ & $3(12.5 \%)$ & 0.109 \\
\hline \multicolumn{4}{|l|}{ Surgical method } \\
\hline Cold steel & $353(93.4 \%)$ & $22(91.7 \%)$ & 0.670 \\
\hline Coblation w RF & $12(3.2 \%)$ & $0(0.0 \%)$ & 1.000 \\
\hline Dissection with diathermy & $3(0.8 \%)$ & $2(8.3 \%)$ & 0.031 \\
\hline \multicolumn{4}{|l|}{ Method of hemostasis } \\
\hline Compression & $310(82.0 \%)$ & $20(83.3 \%)$ & 0.767 \\
\hline Bipolar diathermy & $334(88.4 \%)$ & $24(100 \%)$ & 0.241 \\
\hline Ligature & $23(6.1 \%)$ & $5(20.8 \%)$ & 0.022 \\
\hline Local anesthetic w adrenalin & $284(75.1 \%)$ & $16(66.7 \%)$ & 0.443 \\
\hline Tranexamic acid & $27(7.1 \%)$ & $3(12.5 \%)$ & 0.155 \\
\hline \multicolumn{4}{|l|}{ Miscellaneous } \\
\hline TE à chaud & $43(11.4 \%)$ & $2(8.3 \%)$ & 1.000 \\
\hline Regional hospital & $267(70.6 \%)$ & $16(66.7 \%)$ & \multirow{2}{*}{0.680} \\
\hline University hospital & $111(29.4 \%)$ & $8(33.3 \%)$ & \\
\hline Operating time only TE & $36(28 ; 46)$ & $34(31 ; 50)$ & 0.932 \\
\hline
\end{tabular}

The patients who suffered postoperative bleeding were compared to non-bleeding patients. No distinction regarding early or late hemorrhage was made, thus all hemorrhages resulting in some sort of intervention immediately after anesthesia up to 30 days postoperatively were included. Patients who only suffered minor problems with bloodmixed saliva postoperatively and returned home as planned were not included.

Since the majority of patients were children or young adults, we evaluated if age affected the risk of bleeding. All patients at least 18 years of age were categorized as adults. In addition, any potential difference between the sexes was analyzed, as well as differences in patient selection and surgical indication. The surgical indications were divided into the following categories: obstruction, chronic or recurring tonsillitis, acute/former peritonsillar abscess, complication of systemic disease, suspected malignancy and 'other indication' (such as branchial cleft cysts).

We also wanted to evaluate if the experience of the surgeon could affect the risk of postoperative bleeding. Surgeons were divided into the following categories: 'Junior resident', 'Senior resident' and Specialist/ Consultant. The cut off between junior and senior resident was 30 out of the 60 months of clinical experience required to become a specialist. Furthermore, operating time was evaluated for patients who only had TE (thus excluding those with other concurrent surgery). Surgical techniques and methods of hemostasis were analyzed and divided into cold steel, coblation with radiofrequency and dissection with diathermy. Emergency tonsillectomy due to peritonsillar abscess (TE à chaud) was suspected to increase the risk of bleeding and was therefore documented. Methods of hemostasis were divided into compression, diathermy, ligature, and local anesthesia with adrenaline. Use of tranexamic acid was also recorded.

We recorded the prevalence of smoking, BMI, comorbidity and previous surgeries in the area, e.g. previous TT for all patients. Since children's reference values for BMI vary widely with age, the measure of ISO-BMI was used to categorize patients as normal weight or overweight (including obesity and severe obesity). In order to enable analysis of the entire material the adults were also categorized as normal $(\mathrm{BMI}<25)$ or overweight $(\mathrm{BMI} \geq 25)$. The following comorbidity variables were included: Hypertension, oral anticoagulants, coagulopathies, diabetes, and ADHD.

The primary outcome measure was postoperative bleeding. Secondary outcome measures were postoperative infection, bleeding causing readmission, number of extra days in hospital, time until bleeding, reoperation in general anesthesia, and comparing bleedings in 2017 with 2018.

\section{Statistical methods}

Continuous variables were summarized as medians with lower and upper quartile. Their distributions were tested with the Shapiro-Wilks test. Normally distributed data was analyzed with Student's t-test, nonnormally distributed data with the Mann-Whitney U test. Categorical variables were presented as numbers and percentages and analyzed with the Chi-Square-test, or Fisher's exact test when at least one cell had an expected value less than 5. A logistic regression analysis was carried out to identify risk factors associated with bleeding. The parameters that individually met $\mathrm{p}<0.1$ were included to analyze their association to each other. In the case of a significant association with a Pearson correlation test the parameter least associated with postoperative bleeding was removed. Thereafter, backward stepwise regression was carried out, in which the weakest variable of the model was removed in each step until only variables with $\mathrm{p}<0.05$ remained. A linear regression analysis was used for the continuous variables age and BMI for adults. A p-value $<0.05$ was considered statistically significant. Adults and children were analyzed together as well as separately.

\section{Results}

Of the 402 patients who underwent TE during 2017-2018, 24 had postoperative bleeding (6.0\%) (Table 1). Postoperative infection occurred in 16 patients $(4.0 \%)$.

The number of readmissions due to bleeding was 23 (5.7\%) and resulted in 27 extra days in hospital. The median time until bleeding occurred was 5.5 days postoperatively. Ten cases required reoperation in surgical theatre (2.5\%).

When comparing the bleeding group with the reference group using univariate analysis, statistically significant differences were identified for age $\geq 18$ years $(\mathrm{p}=0.013)$, hypertension $(\mathrm{p}=0.001)$, dissection with diathermy $(\mathrm{p}=0.031)$ and hemostasis with ligature $(\mathrm{p}=0.022)$. Other 
parameters close to statistical significance were smoking $(\mathrm{p}=0.056)$ and postoperative infection $(\mathrm{p}=0.057)$. After multivariate regression analysis only hypertension and dissection with diathermy remained significant risk factors, with odds ratios of 7.07 (95\% confidence interval: $2.39 ; 20.91)$ and $9.55(1.32 ; 68.92)$ respectively (Table 2$)$. The continuous variables age and BMI for adults were not significantly correlated to risk of bleeding in a linear regression analysis.

Surgical indication did not differ between the bleeding group and the reference group. The median time for surgery with only TE (without other concurrent surgery) was 36 minutes for the reference group and 34 minutes for the bleeding group. The majority of TE was performed with cold technique $(93.3 \%)$, and $4.0 \%$ by dissection with diathermy or coblation. In ten patients, the surgical method did not appear in the medical records.

There was no significant difference in bleeding risk based on surgical experience (Table 3 ). The category with highest bleeding frequency was specialist/consultant, 14/198 (7.1\%), followed by junior resident with 7/101 (6.9\%) and lowest for senior resident with 3/103 (2.9\%). Median operating time for TE alone was 45 minutes for junior residents, 32.5 minutes for senior residents and 33 minutes for specialists/consultants, indicating that junior residents required significantly more time than more senior colleagues $(\mathrm{p}=0.000)$.

In $2017,17 / 177(9.6 \%)$ suffered postoperative bleeding and in $2018,7 / 225(3.1 \%)(\mathrm{p}=0.006)$ (Table 4). Variables that differed between the 2017 and 2018 groups included percentage of patients with hypertension $(\mathrm{p}=0.001)$ and ligation $(\mathrm{p}=0.007)$. 'Other indication' $(\mathrm{p}=0.053)$ and coblation $(\mathrm{p}=0.053)$ were close to statistical significance.

\section{Discussion and conclusion}

Among the 402 patients who underwent TE 2017-2018 the postoperative bleeding frequency within 30 days was $6.0 \%$, similar to the national average of $6.2 \%$ for the same period according to NTSRS [1].

A statistically significant correlation to postoperative bleeding was found for age $\geq 18$ years, hypertension, dissection with diathermy and ligature in univariate analysis, but only hypertension and dissection with diathermy remained significant after multivariate regression. Cold steel was standard practice, used in $93.3 \%$ of the cases in this study. Only five patients underwent surgery using dissection with bipolar diathermy, resulting in two postoperative bleedings (40\%), indicating a tenfold risk of bleeding in this very small group. However, the results are in accordance with the sixfold risk of bleeding after dissection with bipolar diathermy demonstrated by Lundström et al. [15] and those

Table 2. Multivariate analysis of risk factors for postoperative bleeding. The significant factors in a multivariate logistic regression analysis with backwards stepwise regression. p-value calculated using Wald test. The following factors were included: Hypertension, Dissection with diathermy, Smoking.

\begin{tabular}{|l|c|c|}
\hline & Odds ratio (95\% CI) & p \\
\hline Hypertension & $7.07(2.39 ; 20.91)$ & 0.000 \\
\hline Dissection with diathermy & $9.55(1.32 ; 68.92)$ & 0.025 \\
\hline
\end{tabular}

Table 3. Univariate analysis comparing patients with and without postoperative bleeding.

\begin{tabular}{|l|l|l|l|l|}
\hline Surgeon & $\begin{array}{l}\text { Reference } \\
\text { group, n=378, } \\
\mathbf{( \% )}\end{array}$ & $\begin{array}{l}\text { Bleeding, n=24, } \\
\mathbf{( \% )}\end{array}$ & $\mathbf{p}(\mathbf{2 \times 2}$ Chi-2) & p (3x2 Chi-2) \\
\hline Junior resident & $94(93.1 \%)$ & $7(6.9 \%)$ & 0.638 & \multirow{2}{*}{0.315} \\
\hline Senior resident & $100(97.1 \%)$ & $3(2.9 \%)$ & 0.129 & \\
\hline $\begin{array}{l}\text { Specialist/ } \\
\text { consultant }\end{array}$ & $184(92.9 \%)$ & $14(7.1 \%)$ & 0.359 & \\
\hline
\end{tabular}

Table 4. Univariate analysis comparing patients who underwent TE in 2017 to 2018 Age presented as the median (lower and upper quartile). Other variables are presented as numbers (percentages).

\begin{tabular}{|c|c|c|c|}
\hline & $2017 n=177$ & $2018 n=225$ & $\mathrm{p}$ \\
\hline Bleeding & $17(9.6 \%)$ & $7(3.1 \%)$ & 0.006 \\
\hline \multicolumn{4}{|l|}{ Baseline characteristics } \\
\hline Age & $25(16 ; 44)$ & $22(15 ; 37)$ & 0.181 \\
\hline Age $\geq 18$ years & $126(71.2 \%)$ & $151(67.1 \%)$ & 0.388 \\
\hline Male & $85(48.0 \%)$ & $107(47.6 \%)$ & 0.926 \\
\hline Hypertension & $17(9.6 \%)$ & $5(2.2 \%)$ & 0.001 \\
\hline Diabetes & $6(3.4 \%)$ & $3(1.3 \%)$ & 0.190 \\
\hline ADHD & $2(1.1 \%)$ & $4(1.8 \%)$ & 0.698 \\
\hline Smoking & $17(10.1 \%)$ & $19(9.1 \%)$ & 0.736 \\
\hline Oral anticoagulant & $8(4.5 \%)$ & $6(2.7 \%)$ & 0.314 \\
\hline Overweight & $87(50.9 \%)$ & $99(44.6 \%)$ & 0.216 \\
\hline Postoperative infection & $9(5.1 \%)$ & $7(3.1 \%)$ & 0.309 \\
\hline \multicolumn{4}{|l|}{ Indication } \\
\hline Obstruction & $17(9.6 \%)$ & $30(13.3 \%)$ & 0.248 \\
\hline Chronic tonsillitis & $62(35.0 \%)$ & $68(30.2 \%)$ & 0.306 \\
\hline Acute/former peritonsillar abscess & $44(24.9 \%)$ & $62(27.6 \%)$ & 0.542 \\
\hline Complication of systemic illness & $1(0.6 \%)$ & $1(0.4 \%)$ & 1.000 \\
\hline Suspected malignancy & $34(19.2 \%)$ & $38(16.9 \%)$ & 0.547 \\
\hline Other indication & $13(7.3 \%)$ & $7(3.1 \%)$ & 0.053 \\
\hline \multicolumn{4}{|l|}{ Surgical method } \\
\hline Cold steel & $165(93.2 \%)$ & $210(93.3 \%)$ & 0.964 \\
\hline Coblation w RF & $2(1.1 \%)$ & $10(4.4 \%)$ & 0.053 \\
\hline Dissection with diathermy & $3(1.7 \%)$ & $2(0.9 \%)$ & 0.658 \\
\hline \multicolumn{4}{|l|}{ Method of hemostasis } \\
\hline Compression & $151(88.3 \%)$ & $179(82.9 \%)$ & 0.134 \\
\hline Bipolar diathermy & $155(91.7 \%)$ & $203(92.3 \%)$ & 0.841 \\
\hline Ligation & $19(11.2 \%)$ & $9(4.1 \%)$ & 0.007 \\
\hline Local anesthetic $\mathrm{w}$ adrenaline & $121(71.6 \%)$ & $179(81.0 \%)$ & 0.029 \\
\hline \multicolumn{4}{|l|}{ Miscellaneous } \\
\hline TE à chaud & $16(9.0 \%)$ & $29(12.9 \%)$ & 0.224 \\
\hline Regional hospital & $126(71.2 \%)$ & $157(69.8 \%)$ & \multirow{2}{*}{0.759} \\
\hline University hospital & $51(28.8 \%)$ & $68(30.2 \%)$ & \\
\hline Operating time only TE & $35(27.5 ; 47.5)$ & $36(29 ; 46)$ & 0.691 \\
\hline \multicolumn{4}{|l|}{ Surgeon } \\
\hline Junior resident & $38(21.5 \%)$ & $63(28.0 \%)$ & 0.134 \\
\hline Senior resident & $50(28.2 \%)$ & $53(23.6 \%)$ & 0.285 \\
\hline Specialist/consultant & $89(50.3 \%)$ & $109(48.4 \%)$ & 0.714 \\
\hline
\end{tabular}

of Söderman et al. [13] where dissection with bipolar scissors was associated with a fourfold increase in risk of bleeding.

Hsueh et al. [6] found that hypertension was associated with a 2.2fold risk for readmission due to postoperative bleeding in multivariate analysis, compared to a sevenfold increased risk, in our study. It is possible that patients with hypertension have higher pressure in the blood vessels in the tonsillar fossa increasing the risk of bleeding. On the other hand, hypertension was correlated with age, previously shown to be associated with decreased healing capabilities [18], and maybe correlated to comorbidity or lifestyle factors not identified in this study.

Ligation as a hemostatic method was significantly correlated with an increased risk of bleeding $(\mathrm{p}=0.022)$, but not after multivariate regression. Ligation is often used during difficult intraoperative bleeding and may therefore be an effect rather than a cause of bleeding. Windfuhr et al. [19] saw similar bleeding rates after hemostasis using bipolar coagulation (5.2\%) compared to suture ligation (4.5\%) in 3.658 patients who all underwent TE using cold steel. No study compared ligation to simple compression. The hemostatic methods 
diathermy and compression were mostly used in our clinic, followed by injection and/or compression with adrenaline, with or without local anesthetic, followed by ligation. None of the hemostatic methods were statistically significant for bleeding after multivariate regression, opposing the results of Söderman et al. [13] showing an increased risk of postoperative bleeding after use of diathermy in a study on 15.000 TE patients.

Smoking was not significant in the multivariate regression analysis, possibly due to the modest sample size. Cinnamon et al. [8] and Seyhun et al. [9] saw significantly higher risks of bleeding after TE in smokers, as did Giger et al. [20] after TE à chaud in smokers. A more rigid antismoking recommendation preoperatively could possibly reduce the risk of bleeding after TE, even though smoking was not significantly correlated to bleeding in this study.

Only two of 125 children (1.6\%) bled postoperatively compared to 22 of 278 adults $(7.9 \%)(\mathrm{p}=0.013)$. Age was associated to bleeding in the univariate analysis, but not in the multivariate analysis, due to its strong correlation with hypertension. Male sex was a risk factor for bleeding according to Coordes and Windfuhr [4,5], but not significant in our study.

Longer surgeries could potentially increase the risk of bleeding, as could the surgeon's experience. TE is often not the only procedure during an operation, but part of combined procedures such as a workup for a suspected malignancy, neck cyst or adenotonsillectomy. We compared the duration of surgery in patients who only underwent TE to see if there was a difference between patients who bled and others, but no significant difference was found. Duration of surgery could however be a difficult parameter to analyze, since problematic surgery takes more time, or rushed surgery could lead to an increased risk of bleeding.

Elinder et al. [2] saw an increased risk of bleeding in patients with infectious indication for surgery before, but not after, correcting for other factors and Østvoll et al. [12] found that infectious indication was associated with an increased risk of bleeding in uni- and multivariate analysis in a study of 256.000 patients. In this study, no surgical indication was a significant risk factor. The indication peritonsillar abscess, and especially TE à chaud, could theoretically entail a higher risk of bleeding due to the acute inflammation or scarring, but in accordance with our findings, other authors did not find a significantly increased risk of bleeding after TE à chaud either [21,22] .

Patient data was evaluated and correlated to the risk of bleeding. Overweight was not significantly associated to an increased risk of bleeding, nor was diabetes, oral anticoagulants, or ADHD. Overweight patients underwent TE more often due to obstruction than repeated infections or suspected malignancy, possibly affecting the risk of bleeding. The median age for patients undergoing TE was relatively low (23 years) and comorbidity hence low. We could not reproduce the results of Hoshino et al. [10] who saw increased risk of bleeding in overweight patients or Spektor et al. [11] who saw an increased risk of bleeding in ADHD patients and older children compared to younger.

Surgical experience had no significant impact on bleeding risk. However, it can be speculated that patient groups differed, and that specialists to a larger extent operated on cancer patients with heavy comorbidity or emergency operations, while residents operated on otherwise healthy and younger patients. It is still an interesting finding, that surgical experience did not influence the risk of bleeding in this study.

Postoperative bleeding is an uncomfortable experience for the patient as well as the doctor and a potentially lethal complication.
Twenty-three patients were readmitted due to postoperative bleeding (5.7\%), resulting in 27 extra days in hospital, and 10 cases of reoperation (2.5\%). Readmission, rehospitalization and reoperation, causes not only personal suffering for the patient, but it is also costly. These costs are however still cheaper than inpatient tonsillectomies with several days of postoperative hospital care that used to be the norm 20 years ago. Furthermore, bleeding complications in this study occurred at day 5 in median, indicating that one or two nights at the hospital postoperatively would not increase safety for the patient.

The bleeding frequency increased in 2017 (9.6\%) and decreased below national average in 2018 (3.1\%). We found a significantly higher percentage of hypertensive patients in 2017 (9.6\%) compared to 2018 (2.2\%) and ligation was used more often 2017 (11.2\%) than 2018 (4.1\%). Variation in patients' comorbidity and hemostasis methods could explain the differences between bleeding frequencies in 2017 and 2018. High numbers of postoperative bleedings in 2017 also sparked a debate on techniques and hemostasis methods among doctors at the clinic, possibly contributing to the low numbers of bleedings in 2018 .

In conclusion, hypertension and dissection with diathermy significantly increased the risk of postoperative bleeding after TE. Interestingly, the experience of the surgeon did not affect the risk of bleeding postoperatively. We believe that awareness about surgical techniques, and extra caution concerning hypertension could affect the number of postoperative bleedings.

\section{Acknowledgements}

A warm Thank You to Professor Torbjörn Ledin and statistician Mats Fredriksson for valuable discussions on statistics, and to nurses Ulla-Maj Wester and Elisabet Carlgren for administrative assistance.

\section{Reference}

1. Nationellt kvalitetsregister för öron-, näs- och halssjukvård. Tonsilloperationsregistret, Statistik [Internet]. Göteborg: Nationellt kvalitetsregister för öron-, näs- och halssjukvård; 2020 [updated 2020-01-30; cited 2020-01-30]. Available from: https:// ton.registercentrum.se/statistik/statistik/p/SkphnLnE

2. Elinder K, Söderman AC, Stalfors J, Knutsson J (2016) Factors influencing morbidity after paediatric tonsillectomy: a study of 18,712 patients in the National Tonsil Surgery Register in Sweden. Eur Arch Otorhinolaryngol 273: 2249-2256. [Crossref]

3. Harju T, Numminen J (2017) Risk factors for secondary post-tonsillectomy haemorrhage following tonsillectomy with bipolar scissors: four-year retrospective cohort study. J Laryngol Otol 131: 155-161. [Crossref]

4. Coordes A, Soudry J, Hofmann VM, Lenarz M (2016) Gender-specific risk factors in post-tonsillectomy hemorrhage. Eur Arch Otorhinolaryngol 273: 4535-4541.

5. Windfuhr JP, Chen YS (2019) Do changing trends in tonsil surgery affect hemorrhage rates? A longitudinal study covering 1,452,637 procedures. Eur Arch Otorhinolaryngol 276: 2585-2593. [Crossref]

6. Hsueh WY, Hsu WC, Ko JY, Yeh TH, Lee CH, et al. (2019) Postoperative hemorrhage following tonsillectomy in adults: Analysis of population-based inpatient cohort in Taiwan. Auris Nasus Larynx 46: 397-406. [Crossref]

7. Tolska H, Takala A, Jero J (2018) Peritonsillar infiltration of lidocaine with adrenaline is associated with increased risk of secondary post-tonsillectomy haemorrhage. $J$ Laryngol Otol 132: 911-922. [Crossref]

8. Cinamon U, Goldfarb A, Marom T (2016) The Impact of Tobacco Smoking Upon Chronic/Recurrent Tonsillitis and Post Tonsillectomy Bleeding. Int Arch Otorhinolaryngol 21: 165-170. [Crossref]

9. Seyhun N, Dizdar SK, Çoktur A, Bektaş ME, Albuz O, et al. (2020) Risk factors for post-tonsillectomy hemorrhage in adult population: Does smoking history have an impact? Am J Otolaryngol 41: 102341. [Crossref]

10. Hoshino T, Tanigawa T, Yanohara G, Murotani K, Horibe Y, et al. (2017) Effect of Body Mass Index on Posttonsillectomy Hemorrhage. Biomed Res Int: 9610267. 
11. Spektor Z, Saint-Victor S, Kay DJ, Mandell DL (2016) Risk factors for pediatric posttonsillectomy hemorrhage. Int J Pediatr Otorhinolaryngol 84: 151-155. [Crossref]

12. Østvoll E, Sunnergren O, Stalfors J (2018) Increasing Readmission Rates for Hemorrhage after Tonsil Surgery: A Longitudinal (26 Years) National Study. Otolaryngol Head Neck Surg 158: 167-176. [Crossref]

13. Söderman AC, Odhagen E, Ericsson E, Hemlin C, Hultcrantz E, et al. (2015) Posttonsillectomy haemorrhage rates are related to technique for dissection and for haemostasis. An analysis of 15734 patients in the National Tonsil Surgery Register in Sweden. Clin Otolaryngol 40: 248-254. [Crossref]

14. Odhagen E, Stalfors J, Sunnergren O (2019) Morbidity after pediatric tonsillotomy versus tonsillectomy: A population-based cohort study. Laryngoscope 129: 2619-2626. [Crossref]

15. Lundström F, Stalfors J, Østvoll E, Sunnergren O (2020) Practice, complications and outcome in Swedish tonsil surgery 2009-2018. An observational longitudinal national cohort study. Acta Otolaryngol 140: 589-596. [Crossref]

16. Blanchford H, Lowe D (2013) Cold versus hot tonsillectomy: state of the art and recommendations. ORL J Otorhinolaryngol Relat Spec 75: 136-141. [Crossref]
17. Pynnonen M, Brinkmeier JV, Thorne MC, Chong LY, Burton MJ (2017) Coblation versus other surgical techniques for tonsillectomy. Cochrane Database Syst Rev: CD004619. [Crossref]

18. Guo S, Dipietro LA (2010) Factors affecting wound healing. J Dent Res 89: 219-229. [Crossref]

19. Windfuhr JP, Verspohl BC, Chen YS, Dahm JD, Werner JA (2015) Post-tonsillectomy hemorrhage--some facts will never change. Eur Arch Otorhinolaryngol 272 1211-1218. [Crossref]

20. Giger R, Landis BN, Dulguerov P (2005) Hemorrhage risk after quinsy tonsillectomy. Otolaryngol Head Neck Surg 133: 729-734. [Crossref]

21. Collison PJ, Mettler B (2000) Factors associated with post-tonsillectomy hemorrhage. Ear Nose Throat $J$ 79: 640-2, 644, 646 passim. [Crossref]

22. Windfuhr JP, Chen YS (2001) Immediate abscess tonsillectomy--a safe procedure? Auris Nasus Larynx 28: 323-327. [Crossref]

Copyright: $(2020$ Knoph K. This is an open-access article distributed under the terms of the Creative Commons Attribution License, which permits unrestricted use, distribution, and reproduction in any medium, provided the original author and source are credited. 